\title{
Energy self-consumption from PV systems: estimations for two office buildings in Krakow (Poland)
}

\author{
Magdalena Jurasz ${ }^{1, *}$, and Jerzy Mikulik ${ }^{1}$ \\ ${ }^{1}$ AGH University, Krakow, Poland
}

\begin{abstract}
The analysis presented in this paper focuses on the energetic aspects of the use of photovoltaic (PV) systems in office buildings. Energy generation from PV system has been simulated on an hourly time scale and compared with the energy demand of two office buildings located in Krakow (southern Poland). The buildings' annual load exceeded $1 \mathrm{GWh}$ in both cases. The analysis dealt with estimating how much energy generated by a PV system can be utilized on-site (self-consumption) and how big the energy surpluses will be (energy generation greater than demand). Capacities of PV systems ranging from 0.1 to $1.0 \mathrm{MW}$ have been considered. Also, the impact of PV generation on the residual load parameters and changes in the maximal monthly and hourly energy demand were investigated. The results show that although the building energy demand is similar (in terms of annual volume of energy consumed) the potential of PV systems to cover it is different. The $100-\mathrm{kW}$ PV system can reduce the observed hourly peak energy demand by $1 \%$ in December but by over $30 \%$ in June (respectively, from $171 \mathrm{kWh}$ to $169 \mathrm{kWh}$, and from $333 \mathrm{kWh}$ to $255 \mathrm{kWh}$ ). Considering the annual patterns of the office buildings' energy demand and PV generation (both have their respective peaks in summer), the application of a PV system changes the office building energy demand pattern significantly from the perspective of the power system operator. After installing $500 \mathrm{~kW} \mathrm{PV}$ in an office building consuming $1 \mathrm{GWh}$ annually, the months with highest demand are no longer in summer but in winter.
\end{abstract}

\section{Introduction}

Power systems across the globe are undergoing dramatic transformation in the search for the ultimate goal of sustainability and minimal environment impact [1]. The changes being seen constitute an increasing share of renewable energy sources in individual countries' energy mixes. The world population is moving from rural to urban areas, which are regions of ever-increasing energy consumption. A recent paper by Jurasz et al. [2] investigating the larger scale renewables-based energy system for Lower Silesia in Poland has shown that there is a significant spatial mismatch between wind energy potential and energy demand; thus, if

* Corresponding author: magda.krzywda01@gmail.com 
wind energy is to be the energy source of choice the distribution network will have to be improved. However, on a spatial scale, wind generation can be replaced by photovoltaics, which can be placed on building roofs. A paper by Dabek and Jurasz [3] indicates that a city of close to $300 \mathrm{~km}^{2}$ has a potential to install PV systems on a roof area exceeding $11 \mathrm{~km}^{2}$ (which translates to exactly $1.1 \mathrm{GW}$ of $\mathrm{PV}$ capacity if $10 \mathrm{~m}^{2}$ are required per $1 \mathrm{~kW}$ of capacity).

Since cities are becoming the major centres of human activity and energy consumption, it is mandatory to ensure that their energy needs are satisfied in a sustainable way [4]. As indicated in the previous paragraph, a huge potential lies in the utilization of PV systems. A recent paper by Mikulik [5] shows that office buildings in Poland are starting to play a significant role as energy consumers. Even more importantly, their energy demand is strongly dependent on meteorological parameters, and positively correlated with irradiation (a driving factor of PV energy generation) [5]. The need to investigate the role of PV systems in office buildings is even higher, as a paper by Jurasz and Campana [6] shows that, in case of energy tariffs in Poland, PV systems can significantly reduce the energy cost in office buildings. Considering the above, the objective of this paper is to investigate the potential of a PV system to cover the electricity load in two office buildings in Krakow (Southern Poland). The analysis focuses on aspects such as self-consumption, peak load reduction and impact on the energy demand curve. The paper provides evidence on the role of PV systems in covering office building loads. The remainder of this paper is organized as follows: the following section presents used data and methods; section 3 discusses and presents the results; and the paper ends with conclusions and some potential future research directions.

\section{Materials and methods}

For the purpose of this study, hourly measurements of electricity demand for 2017 in two office buildings have been used. The measurements are a part of the OBEMS research grant realized at AGH University (Faculty of Management) by Prof. Mikulik and his research group. The details of the office buildings cannot be disclosed for reasons of confidentiality. The solar irradiation and temperature data has been downloaded from http://www.sodapro.com/. Figure 1 presents the time series.

The energy demand from the first building amounted to $1.034 \mathrm{GWh}$ in 2017 , whereas in the second building it was only $3 \mathrm{MWh}$ more. The mean hourly energy demand in both buildings is almost the same and amounts to $118 \mathrm{kWh}$. However, the energy demand standard deviation is higher in the first building, being $49.8 \mathrm{kWh}$ compared to $41.7 \mathrm{kWh}$. In both buildings the maximal energy demand exceeds $400 \mathrm{kWh}$ but the minimal demand is no greater than $40 \mathrm{kWh}$. The majority of daily energy consumption occurs from 8 AM to 5 PM (over $54 \%$ ) and, over the year, occurs in summer (40\% of energy being consumed from May to September).

To estimate the energy generated by a PV installation on an hourly basis the following formulas were applied.

$$
\begin{gathered}
E^{P V}=P^{P V} \frac{H}{H^{S T C}}\left[1-\mu\left(T^{C}-T^{S T C}\right)\right] \eta^{P V} \\
T^{C}=T_{a}+H\left(\frac{T^{N O C T}-20}{8}\right)
\end{gathered}
$$


where: $E^{P V}$ - energy generated by PV system [kWh], $P^{P V}$ - installed capacity if PV system [kW], $H$ - irradiation [kWh], $H^{S T C}$ - irradiation in standard testing conditions [kWh], $\mu$ - temperature-dependent efficiency reducing coefficient [-], $T^{C}$ - operating temperature of PV modules $\left[{ }^{\circ} \mathrm{C}\right], T^{S T C}-\mathrm{PV}$ modules operation temperature in standard testing conditions $\left[{ }^{\circ} \mathrm{C}\right], \eta^{P V}$ - overall efficiency of the PV system [\%], $T_{a}$ - air temperature $\left[{ }^{\circ} \mathrm{C}\right], T^{N O C T}-$ temperature in normal operating conditions $\left[{ }^{\circ} \mathrm{C}\right]$.
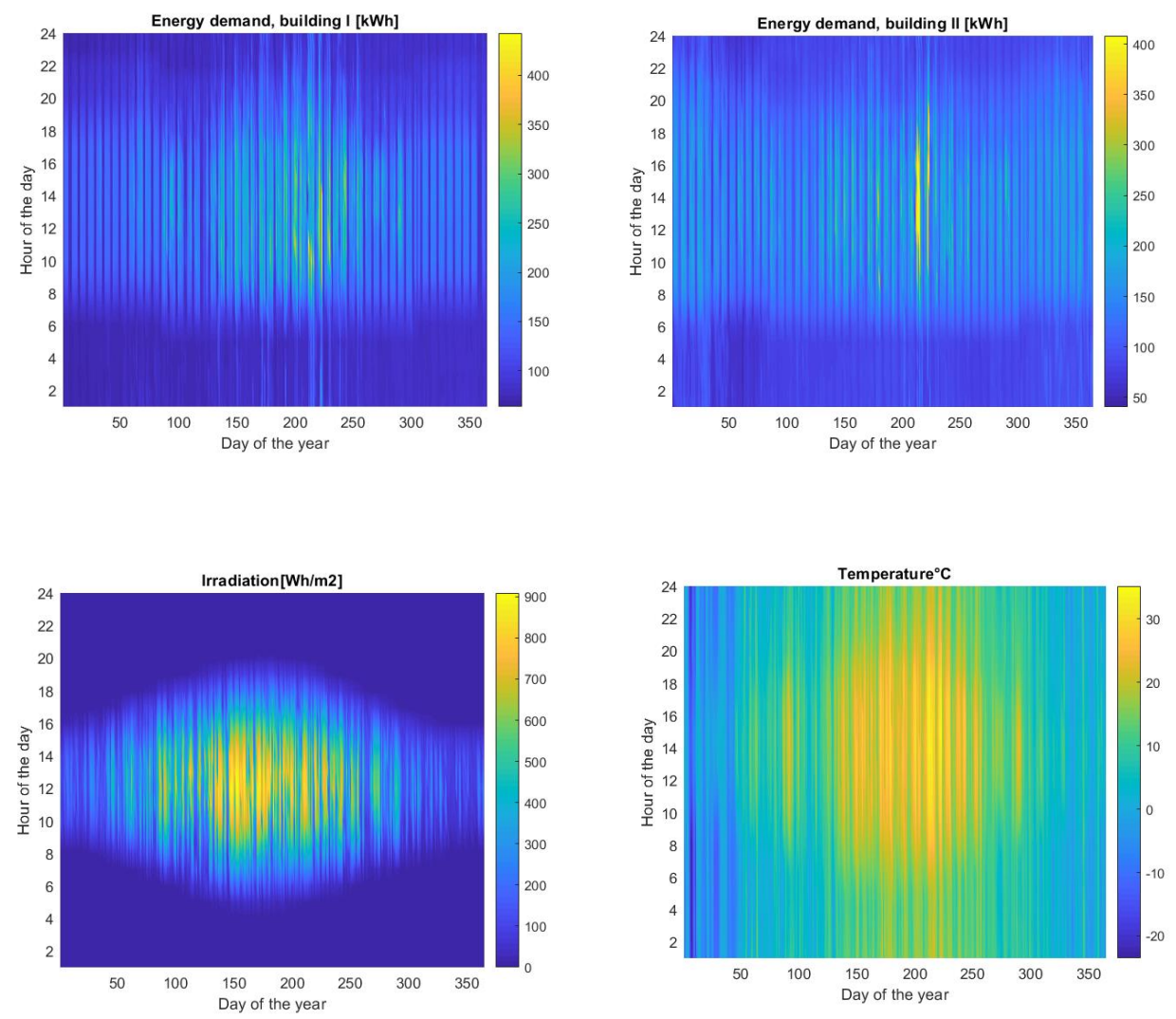

Fig. 1. Spectrum chart of input data for the year 2017.

It was assumed that the modules will be optimally mounted (from the energy generation perspective), namely, facing south at a $30^{\circ}$ inclination. This approach was selected since the objective of this paper was not to investigate the potential of specific buildings to accommodate PV installation. Also, it was not the intention of the authors to investigate the potential of different $\mathrm{PV}$ module orientations, as indicated in the paper by Chattopadhyay et al. [7]. The overall efficiency of the PV system was set to $\eta^{P V}=90 \%$ (this included the losses in the inverter, wiring, etc.), whereas the temperature-dependent efficiency reducing coefficient was $\mu=0.35 \% /{ }^{\circ} \mathrm{C}$. The equations presented above are in line with the recommendation of Duffie and Beckman [8].

Based on Eq. 1 and Eq. 2 it was found that, on a yearly basis, $1 \mathrm{~kW}$ of capacity installed in a PV system will generate $1,060 \mathrm{kWh}$, which results in a capacity factor of $12.1 \%$. Such values are common for this part of Europe [9]. The way how residual load and selfconsumption were calculated are provided in section 3.1. The differences between office 
buildings load profiles results from the variation of the number of employees, buildings orientation or type of activities. The factors driving those differences were not subject of this analysis.

\section{Results and discussion}

This section presents and discusses the results of the conducted analysis. The subsections present the following: self-consumption from PV generation; impact of PV on residual load; changes in annual energy demand patterns; PV potential to reduce monthly peak load.

\subsection{Self-consumption and residual load}

The first part of the analysis focuses on self-consumption and residual load. The former is defined as the ratio of energy generated by a given energy source (PV) to the volume of that energy utilized by the energy consumer (office building). If the energy generation is greater than the energy demand, an energy surplus will occur (which in the case of a grid-connected system will have to be absorbed by the grid, impacting the national load balance [10]. The latter (residual load) is understood as a difference between energy demand and energy supply from PV generator, but if supply is greater than demand the residual load is set to " 0 ".

The values of the parameters presented above are shown in Fig. 2. As can be observed, both have a non-linear relationship with the capacity of the PV system. For PV capacities of up to $150 \mathrm{~kW}$, over $99 \%$ of the energy generated is used to cover the energy demand of the building. When the capacity of the PV system exceeds $0.95 \mathrm{MW}$ and $0.8 \mathrm{MW}$ (for buildings I and II, respectively) the energy self-consumption drops below $50 \%$.

The residual load parameter coincides with self-consumption. As can be seen on the right-hand chart in Fig. 2, in both buildings, with a PV capacity of up to $300 \mathrm{~kW}$, the PV systems have a similar impact on the residual load. However, at a certain point each additional $\mathrm{kW}$ installed in PV systems in building I lowers the residual load. A decrease in the residual load means that the building needs less energy from the national power system.

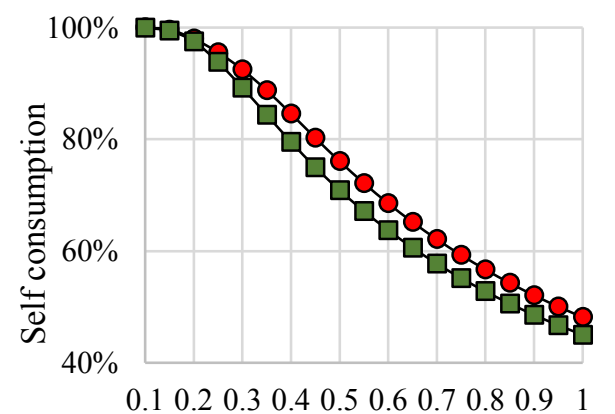

Installed capacity in PV [MW] $\multimap$ Building I $\rightarrow-$ Building II

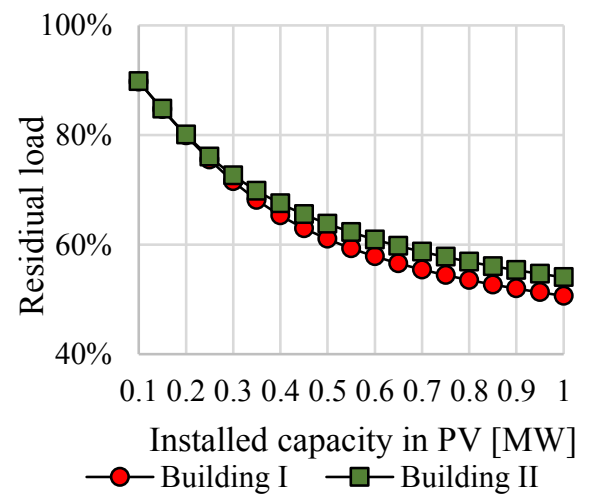

Fig. 2. Energy generated from PV used by the building (left), impact of PV on the building total load (right).

\subsection{Covering the energy demand}

The previous subsection has shown how changing the capacity of the PV system affects self-consumption and residual load. The results were, however, presented on an annual time 
scale. Considering the load and irradiation variability, it is important to investigate this on a shorter, monthly time scale.

Figure 3 shows the sum of monthly electricity demand in both buildings. It shows a clear annual energy demand pattern, with the highest energy consumption from May to August. In the first building the monthly demand ranges from 67 to $112 \mathrm{MWh}$, but from $70 \mathrm{MWh}$ to $104 \mathrm{MWh}$ in the second building. For this specific analysis, a $500 \mathrm{~kW}$ PV system was selected in both cases. As can be observed, it significantly changes the annual demand pattern from peak demand being observed in the summer to peak load in winter. Such a change might also be important from the perspective of the operation of the national power system, especially the Polish one, which is dominated by thermal generation and is beginning to face some power generation capacity constraints during hot summer days. Not surprisingly (considering the irradiation patterns in Fig. 1), the highest reduction in monthly electricity consumption is observed in June. In buildings I and II the energy demand was reduced by $169 \%$ and $158 \%$, respectively, from $99 \mathrm{MWh}$ to $36 \mathrm{MWh}$ and from $89 \mathrm{MWh}$ to $34 \mathrm{MWh}$.
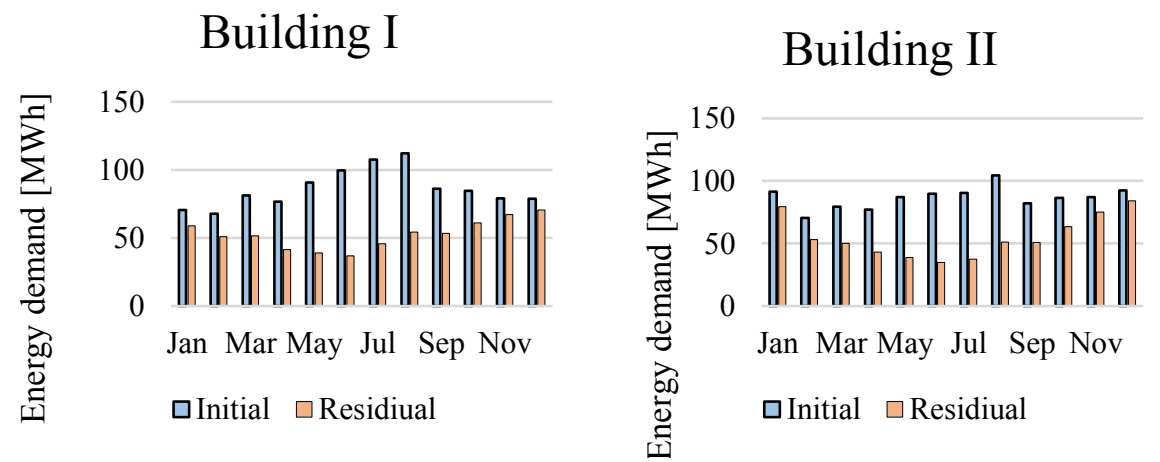

Fig. 3. Energy demand reduction for a 500-kW PV system in both buildings.

\subsection{Changes in monthly maximal loads}

Last but not least, the analysis now focuses on the potential of the PV system to reduce the maximal hourly energy demand observed during individual months. As shown by Jurasz and Campana [6] peak demand plays an important role in the electricity bill in the case of tariffs for office buildings. Jurasz and Campana estimated that PV systems can significantly reduce the peak load and thereby reduce the electricity bill. Accordingly, for Polish electricity tariffs, the owner can declare his peak load for each month of the year, and, if exceeded, a penalty will be imposed. Figures 5 and 6 present the current (blue continues line) peak load during each month and the impact of adding $0.1,0.2$ and so on of PV capacity on its reduction. 


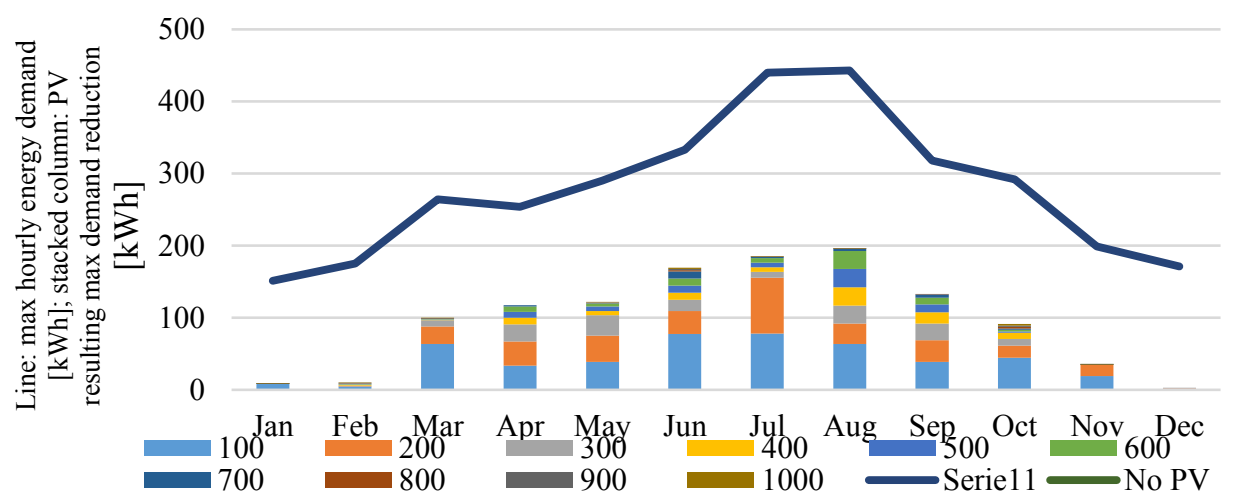

Fig. 4. Impact of adding PV capacity on the reduction of observed hourly maximal energy demand during individual months (Building I).

As can be seen in Fig. 4 and Fig. 5, the buildings exhibit different patterns in terms of maximal hourly energy demand. The patterns differ, but in both cases the maximal values are observed in August, and exceed $400 \mathrm{kWh}$ (significantly in building I, and slightly in building II). Naturally, the potential of the PV system to reduce peak load depends on the match between solar energy availability and the time when the maximal load is observed. As shown in Fig. 4 and Fig. 5, for months like November-February (varies between the two buildings) the additional capacity in PV system does not significantly lower the maximal energy demand. For example, in building I in January, adding $100 \mathrm{~kW}$ of PV reduces the peak load from $151.25 \mathrm{kWh}$ to $143.2 \mathrm{kWh}$, but adding $900 \mathrm{~kW}$ of PV capacity only reduces it by a further $0.7 \mathrm{kWh}$ to $142.5 \mathrm{kWh}$. This clearly shows that the peak load is observed in hours different from the availability/operation of the PV generator. A different situation is observed in (especially) summer months, however. Then, adding $100 \mathrm{~kW}$ and $200 \mathrm{~kW}$ in PV capacity has an immense impact on the peak load. A reduction of as much as $154 \mathrm{kWh}$ (July, building I) can be observed. It must be noted that this potential of PV systems to reduce peak demand is strongly dependent on the match between electricity demand and supply. It is naturally recommended that office buildings with big air-conditioning units should be equipped with PV systems to reduce their impact on the load curve on the national level [5].

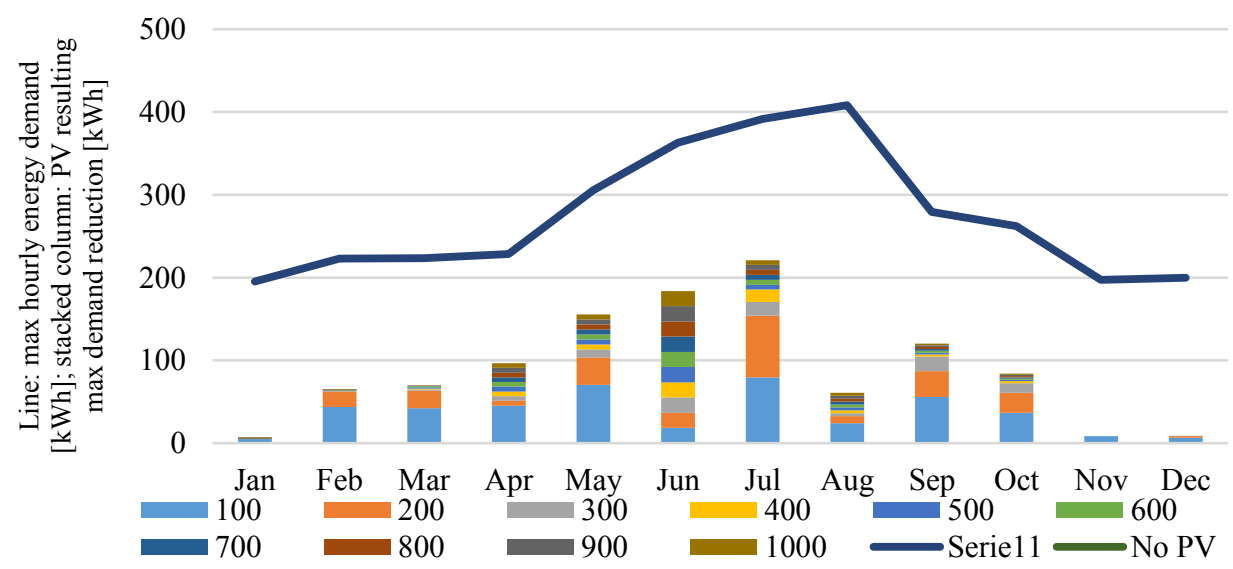

Fig. 5. Impact of adding PV capacity on reducing observed hourly maximal energy demand during individual months (Building II). 


\subsection{Energy flow}

The final part of the analysis briefly presents the issue of the energy flow between an office building with a PV system and the national power system. The PV generator is a nondispatchable energy source and, as such, it has a significant impact on the operation of the national and regional power system. Considering their non-dispatchability and temporal variability of power output, their integration into the power system is a significant challenge [11].

The self-consumption and residual demand analysis presented in Fig. 2 indicates that: a) the PV system is not able to completely cover the electricity demand, and b) not all energy generated by the PV system is consumed by the building/used to cover its demand. If the building is operated in an on-grid mode it means that there is a significant variability in the energy flow direction. Figure 6 presents this issue for both buildings and $500 \mathrm{~kW}$ installed capacity in PV. As can be observed, there is a significant energy surplus (flow from the PV system to the grid) during daytime hours and from the grid to the building during night- time hours. As indicated before, adding a PV system to the building significantly changes the building energy demand pattern. This opportunity should be seriously considered by governmental organizations and power system operators, as PV systems can clearly support the operation of the power system. It is, however, important to note that electricity tariffs may significantly affect the self-consumption rate [12] and also that some new conceptual business models might be needed for such situations [13]. On the other hand, building owners may consider not only a PV system but also, bearing in mind the energy flow, the potential application of energy storage technology [14, 15].
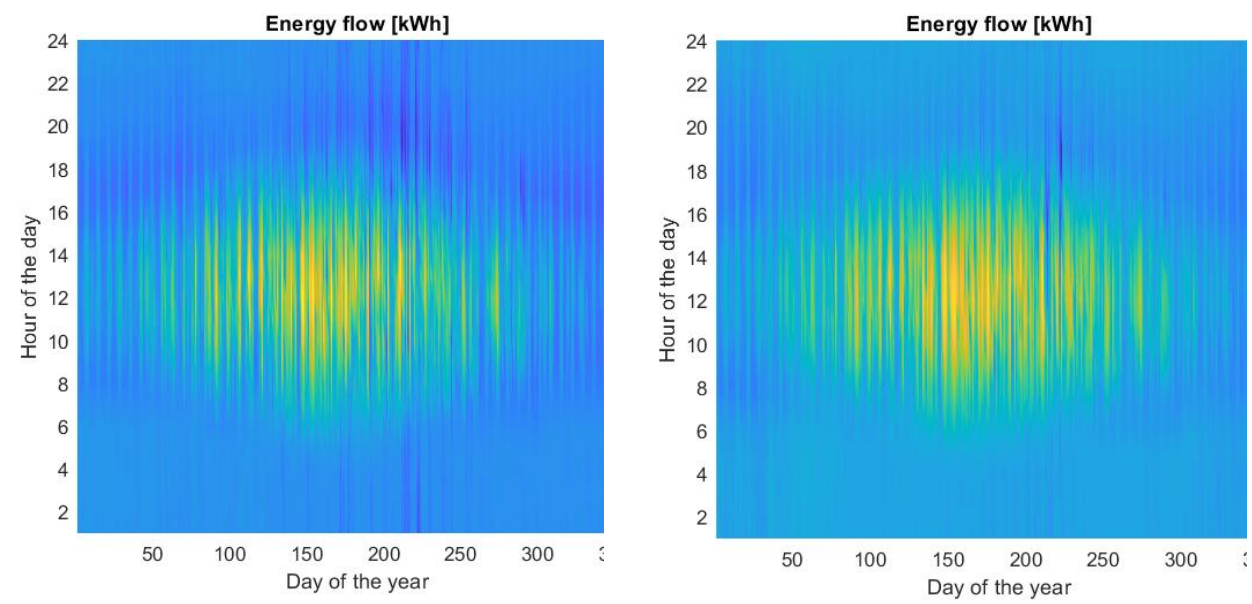

Fig. 6. Energy flow between office buildings (left building I, right building II) with $500 \mathrm{~kW}$ PV installations. Positive values show energy flow to the grid (surplus energy from PV generation), negative values show energy demand of the building being covered from the grid

\section{Conclusions}

This paper reports an outcome of research intending to analyse the impact of PV generation on energy demand in office buildings. Based on real data on hourly energy demand and simulated energy generation from a PV system it was found that, for the considered office buildings, PV systems with capacities up to $200 \mathrm{~kW}$ have very high self-consumption factors 
(meaning that all the generated energy is consumed onsite). Also, adding PV systems to support the office buildings in covering their electricity needs reduces the observed maximal energy demand and significantly alters the annual energy demand curve from peaking in summer to peaking in winter. The results of this research present important evidence that PV systems may not only potentially reduce electricity bills in office buildings (by reducing the peak load, as also shown by Jurasz and Campana [6] but that their impact on the energy demand might be beneficial from the perspective of the national power system. In future research we would like to focus on the economic aspects of PV utilization in office buildings, their hybridization with wind energy and application with energy storage. Our intention is also to increase a portfolio of considered office buildings in order to work on a more representative sample.

\section{References}

1. S. C. Parkinson, M. Makowski, V. Krey, K. Sedraoui, A. H. Almasoud, N. Djilali, Appl. Energ. 210, 477-486 (2018)

2. J. Jurasz, P. B. Dąbek, B. Kaźmierczak, A. Kies, M. Wdowikowski, Energy 161, 183-192 (2018)

3. P. B. Dąbek, J. Jurasz, E3S Web. Conf. 45, 00014 (2018)

4. M. Z. Jacobson, M. A. Cameron, E. M. Hennessy, I. Petkov, C. B. Meyer, T. K. Gambhir, M. L. Miccioli, Sustain. Cities and Soc. 42, 22-37 (2018)

5. J. Mikulik, Sustainability-Basel. 10 (2018)

6. J. Jurasz, P. E. Campana, Sustain. Cities Soc. 44, 871-879 (2019)

7. K. Chattopadhyay, A. Kies, E. Lorenz, L. von Bremen, D. Heinemann, Renew. Energ. 113, 176-189 (2017)

8. J. Duffie, W. A. Beckman, Solar engineering of thermal processes (John Wiley \& Sons, 2013)

9. A. Bugała, K. Bednarek, L. Kasprzyk, A. Tomczewski, E3S Web. Conf. 19, 01002 (2017)

10. J. Jurasz, M. Krzywda, J. Mikulik, E3S Web. Conf. 10, 00059 (2016)

11. J. Jurasz, B. Ciapała, Sol. Energy 173, 675-690 (2018)

12. J. C. Solano, M. C. Brito, E. Caamaño-Martín, Energy Pol. 122, 322-331 (2018)

13. Y. Yang, Y. Zhang, P. E. Campana, J. Yan, Energy Proced. 142, 3182-3193 (2017)

14. P. E., Campana, L. Cioccolanti, B. François, J. Jurasz, Y. Zhang, B. Stridh, Y. Jinyue, 10th International Conference on Applied Energy (ICAE 2018)

15. J. C. Solano, L. Olivieri, E. Caamaño-Martín, Appl. Energy. 206, 249-266 (2017) 